\title{
Epauletten einer Galauniform - Sinnbild des Untergangs der Zarenarmee vor 100 Jahren
}

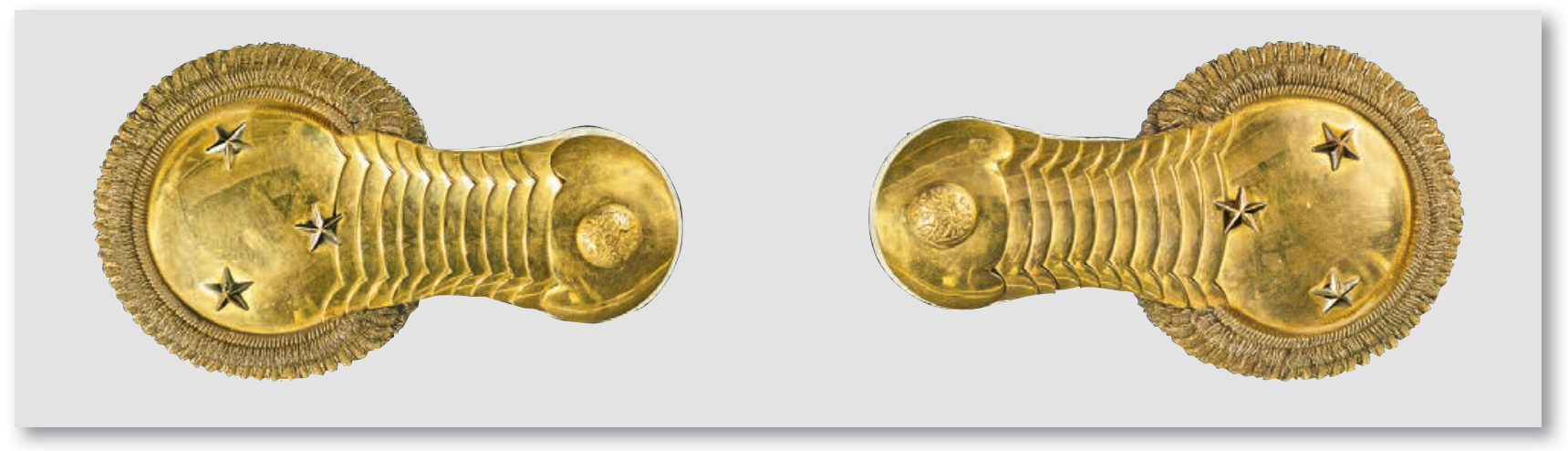

Abb. 1: Epauletten eines Offiziers der Zarenarmee, vermutlich des "Leibgardegrenadier-Regiments zu Pferde" in Stary Peterhof (WLB/BfZ, R 30)

"Werdet diesen Abschaum mit den goldenen Schulterstücken los und wir alle werden euch unterstützen!"1 Mit diesen Worten machte ein russischer Soldat im Sommer 1917 in einer Soldatenversammlung unmissverständlich klar, dass in den Augen vieler Mannschaften die zarischen Offiziere abgewirtschaftet hatten und eine Zukunft der Russischen Armee nur ohne sie denkbar sei. Die Soldaten wollten eigene Offiziere wählen und forderten einen raschen Friedensschluss mit Deutschland, um dem verlustreichen Ersten Weltkrieg ein Ende zu setzen. Vor 100 Jahren waren die Epauletten der Galauniformen im Rahmen der Russischen Revolution zum Symbol für die verhasste Offiziersklasse geworden.

Übergriffe auf Offiziere des alten Regimes beschränkten sich im Revolutionsjahr 1917 vielfach nicht auf das demonstrative Abreißen von Schulterstücken und anderen Rangabzeichen. Offizieren wurde das Misstrauen ausgesprochen, sie wurden abgesetzt und verhaftet. Einige Armeeeinheiten forderten die Todesstrafe für die vermeintlich konterrevolutionären Verräter, und einige Offiziere wurden sogar gelyncht.

Hintergrund für diesen Hass war, dass die Offiziere in den Augen vieler Soldaten das alte System repräsentierten, das im Zuge der Revolution abgeschafft werden sollte. Sie waren für sie Inbegriff der Unterdrückung, der Privilegierung der oberen Klassen und der sinnlosen Opferung von Menschenleben in einem Krieg, dessen Ziele nicht mehr zu überzeugen vermochten und der von der Russischen Armee nicht mehr zu gewinnen war. Die Abdankung des Zaren am 15. März 1917 änderte an der Stimmungslage wenig, da die nun amtierende Provisorische Regierung den Krieg fortsetzte, die Versorgungslage schlecht blieb und die alten zarischen Offiziere im Amt blieben. Im Sommer 1917 heizte sich die ohnehin angespannte Stimmung weiter auf, als die Regierung eine neue Offensive startete. Die zarischen Offiziere missachteten die von den Soldaten gewählten Repräsentanten, hatten aber gleichzeitig nicht mehr die Autorität, militärische Befehle durchzusetzen. Die Kerenski-Offensive, die zur Wiederherstellung der Ordnung hatte dienen sollen, wurde ein großer Fehlschlag und trieb die Auflösung der Armee zusätzlich voran. Die Lage spitzte sich noch weiter zu, als General Lawr Georgijewitsch Kornilow Anfang September 1917 versuchte, Truppen nach Petrograd (heute St. Petersburg) zu verlegen und Gerüchte kursierten, dass er versucht habe, eine Militärdiktatur zu errichten und der Revolution ein Ende zu bereiten. Den Offizieren wurde vielerorts vorgeworfen, Kornilow zu unterstützen oder zumindest mit seinen konterrevolutionären Ideen zu sympathisieren. ${ }^{2}$ Unter Lenins Führung erhielten die Bolschewiki nun vermehrt Zulauf. Sie übernahmen kurz darauf im Zuge der Oktoberrevolution die

1) "Get rid of this gold shoulder-boarded scum and we'll all support you!" Wildman, Allan K.: The end of the Russian imperial army, Bd. 2: The road to Soviet power and peace, Princeton, N.J. 1987, S. 217.

2) Wildman, The end of the Russian imperial army, Bd. 2, S. 211-217. 
Macht und schlossen am 15. Dezember 1917 einen Waffenstillstand mit Deutschland.

Die Bibliothek für Zeitgeschichte (BfZ) verfügt über interessante Objekte aus der Zeit, als Offiziere der Zarenarmee noch nicht als "Abschaum mit den goldenen Schulterstücken“ galten, sondern als ihre Schulterstücke noch Zeichen ihres hohen militärischen und gesellschaftlichen Ranges darstellten. So befinden sich in den Sammlungen der BfZ ca. $16 \mathrm{~cm}$ lange und $9 \mathrm{~cm}$ breite, golden glänzende

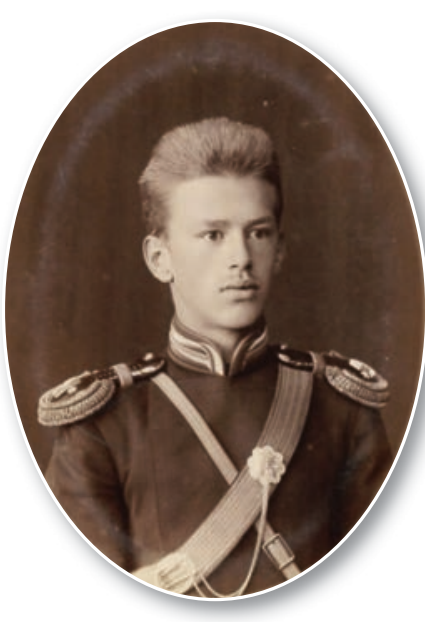

Messing-Epauletten, die Teil der Gala-Uniform waren (Abb. 1). Ob der Offizier, dem diese Schulterstücke gehörten, Probleme mit revoltierenden Soldaten hatte, ist nicht überliefert, denn der Besitzer ist nicht bekannt.

Abb. 2: Russischer Offizier in der Galauniform des Leibgarde-Dragonerregiments (WLB/BfZ R 362)

Die Epauletten sind Teil des so genannten „Zarenarchivs“, das 1964 mit Unterstützung des Bundesministeriums für wissenschaftliche Forschung, des Stifterverbands für die deutsche Wissenschaft sowie der Fritz-Thyssen-Stiftung aus Schweden in die Bibliothek kam. ${ }^{3}$ Die Sammlung gehörte einem ehemaligen Stabskapitän der zarischen Armee, der über 10.000 Fotografien, Postkarten, Bücher, Karten und weitere Dokumente zur Geschichte Russlands zwischen 1880 und 1921 zusammengetragen hatte. Das Archiv enthält insbesondere Bilder aus der Regierungszeit des letzten russischen Zaren. Es handelt sich wohl um eine der größten in sich geschlossenen Sammlungen in Deutschland über das Leben am Hofe Nikolaus II.

In der Sammlung finden sich in großem Umfang Darstellungen des Offizierslebens in der zarischen Armee. Der einzigartige Bestand an Bildquellen dokumentiert sowohl militärisches Leben der Vorkriegszeit als auch des Ersten Weltkriegs. Zum Bürgerkrieg in den Jahren 1917-1921 sowie zur

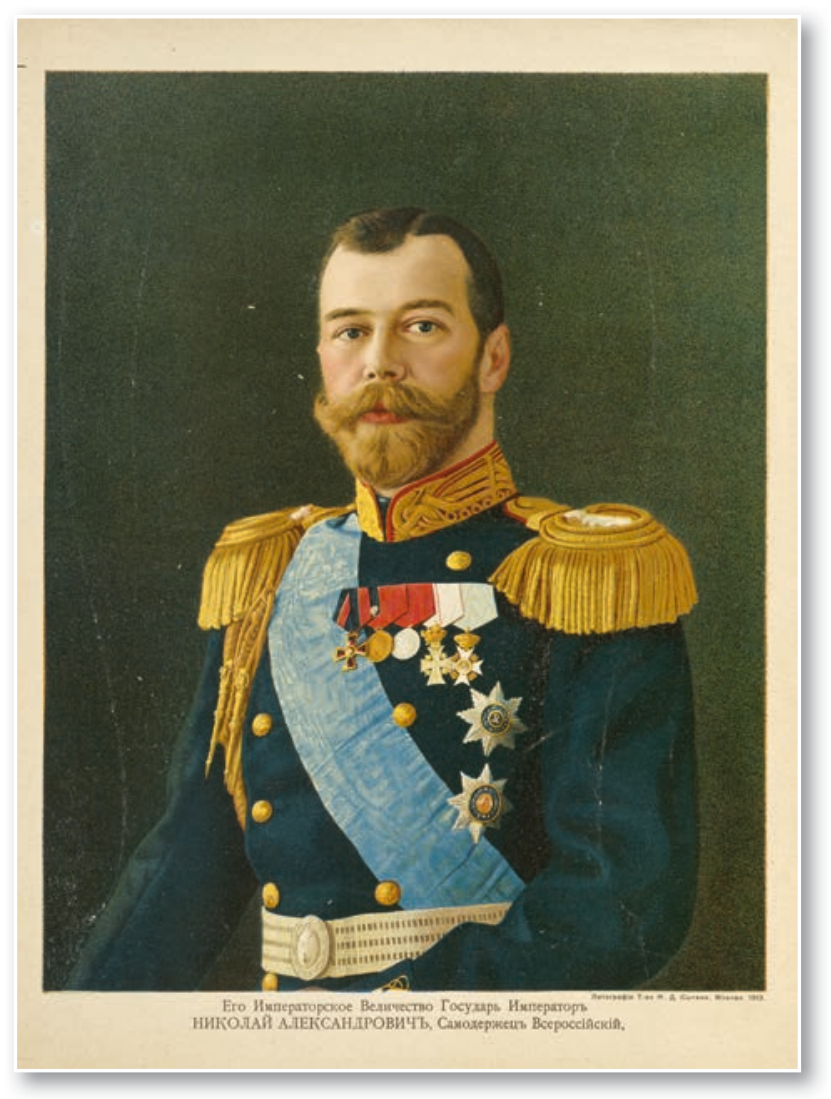

Abb. 3: Zar Nikolaus II., Lithographie, Moskau 1913 (WLB/BfZ R 121)

darauffolgenden Zeit des Exils russischer Offiziere und Adeliger liegen ebenfalls Materialien vor. Die Sammlung vermittelt somit einen lebendigen Eindruck von der Welt der Offiziere in der Zarenarmee, die 1917 unterging.

100 Jahre später tut sich die russische Regierung schwer damit, der Russischen Revolution angemessen zu gedenken. In der Frage der Bewertung der Revolution ist die russische Bevölkerung tief gespalten. Die Regierung möchte jedoch nach Möglichkeit gesellschaftliche und politische Fragmentierungen nicht thematisieren, sondern ist bestrebt, in der Öffentlichkeit die Einigkeit Russlands hervorzuheben. Die Erinnerung an das Weltereignis Russische Revolution fällt daher bisher eher spärlich aus. Am 24. Oktober 2017 wird sich die Bibliothek für Zeitgeschichte in ihrer Vortragsreihe mit dem schwierigen Gedenken an die Revolution im heutigen Russland auseinandersetzen. Als Experte ist Professor Dr. Nikolaus Katzer eingeladen, der seit 2010 das Deutsche Historische Institut in Moskau leitet. Das Thema seines Vortrags im Hauptstaatsarchiv lautet: „Vom Zarenadler zur Roten Fahne. Die Russische Revolution als kontroverses Erbe." 